ORIGINAL ARTICLE

\title{
Higher incidence of SIDS at weekends, especially in younger infants
}

\author{
J A Mooney, P J Helms, I T Jolliffe
}

Arch Dis Child 2004;89:670-672. doi: 10.1136/adc.2002.023408

See end of article for authors' affiliations

authe.....................

Correspondence to: Professor P J Helms, Department of Child Health, Medical School, University of Aberdeen, Foresterhill, Aberdeen AB25 2ZD, UK. p.j.helms@abdn.ac.uk

Accepted 14 October 2003
Background: An increased incidence of sudden infant death syndrome (SIDS) at weekends has been previously noted, although it has not been found in all studies. Where a weekend effect has been found it is most prominent on Sundays.

Aim: To identify the magnitude of this effect in British data before and after the fall in prevalence associated with the "back to sleep" campaign.

Methods: Aggregated data from England \& Wales, Scotland, and Northern Ireland for the years 198698 during which there were 12762 deaths from SIDS were examined.

Results: Comparing the periods before (1986-90) and after (1993-98) the fall in incidence associated with the "back to sleep" campaign, the percentage of infants dying at the weekend in the later period $(32.24 \%)$ was slightly greater than for the earlier period $(31.30 \%)$, although this difference was not statistically significant. In both periods the observed weekend incidences were significantly higher than the expected weekend percentage of $28.6 \%$. Although the proportion of infants aged $\leqslant 4$ months and $\geqslant 5$ months at death did not change between the two periods, the weekend effect was more marked in the younger infants, particularly in the 1993-98 period. There was no consistent Saturday effect. In 1993-98 deaths appeared to be more evenly distributed throughout the week for infants $\geqslant 5$ months.

Conclusion: The excess of SIDS at weekends still appears to be present despite the overall fall in prevalence associated with the "back to sleep" campaign. Increased risks at weekends might have implications for support to high risk families.
A $\mathrm{n}$ increased weekend incidence of SIDS has been found in some $e^{1-4}$ but not all studies. ${ }^{5}$ In two small studies weekend deaths, as a percentage of all weekday deaths, have been reported at $42 \%$ and $34 \%$ respectively against the expected $28.6 \%,{ }^{12}$ and with more deaths reported on a Sunday than any other day of the week. It was noted that sharing a bedroom with an adult seemed to have less of a protective effect at the weekend; suggestions given for this finding were that parents might be more relaxed at the weekend and so sleep more deeply. ${ }^{2}$ Other possible explanations offered for this effect in further retrospective observational studies were that infants may receive less attention at weekends, compared to during the week, ${ }^{3}$ and that parents may be less willing to seek medical help at the weekend for apparently minor illnesses. ${ }^{4}$ However, a study in two English regions between 1993 and 1996, ${ }^{5}$ and in a USA study no significant differences between the numbers of deaths on different days of the week were found. ${ }^{56}$

We therefore sought to clarify this issue in a data set from all of the constituent parts of the UK, namely England, Wales, Scotland, and Northern Ireland, with particular reference to any changes that might have occurred since the "back to sleep" campaign in the early 1990s.

\section{SUBJECTS AND METHODS}

Available data included day in week and month of death and age for infants with any mention of SIDS on the death certificate from the UK (England \& Wales, Scotland, and Northern Ireland) for the period 1986 to 1998. Data from England and Wales was provided by the Office for National Statistics, for Scotland by the Scottish Cot Death Trust, and for Northern Ireland by the Registrar General Office. During this period, there were 12762 deaths from SIDS in the UK. The numbers in the successive years were: $1986(\mathrm{n}=1718)$; $1987(\mathrm{n}=1732) ; 1988 \quad(\mathrm{n}=1778) ; 1989(\mathrm{n}=1526) ; 1990$ $(\mathrm{n}=1371) ; 1991(\mathrm{n}=1111) ; 1992(\mathrm{n}=584) ; 1993(\mathrm{n}=553)$;
$1994 \quad(\mathrm{n}=527) ; 1995 \quad(\mathrm{n}=472) ; 1996 \quad(\mathrm{n}=503) ; 1997$ $(\mathrm{n}=492) ; 1998(\mathrm{n}=395)$. To determine whether the weekend incidence had changed since the "back to sleep" campaign, the data were analysed in two periods: 1986-90 (before the fall in incidence) and 1993-98 (after the fall had stabilised). The effect of age at death was also examined by grouping the infants into those $\leqslant 4$ months of age at death and those $\geqslant 5$ months of age. This age grouping was used as it reflected our own and others' work which suggested that infants dying at 3 months of age or less appear to have different features than those in the older age groups. ${ }^{78}$ Although the majority of previous studies had found an increased weekend incidence in SIDS we made no assumptions as to the direction in the present data, and therefore a two sided hypothesis test on proportions was performed in order to determine whether there are any particular days and particularly at weekends, deaths were significantly different than expected by chance.

\section{RESULTS}

Table 1 gives the percentages of weekend deaths for all infants before and after the "back to sleep" campaign; it can be seen that in each period there were significantly more weekend deaths than expected by chance. There were more deaths on Sundays than Saturdays in both periods, and although the Saturday effect was significant in 1993-98, it failed to achieve significance in 1986-90. There was a slight but non-significant $(p=0.357)$ increase in overall percentage of weekend deaths in the later compared to the earlier period.

The weekend effect was more apparent in the younger infants ( $\leqslant 4$ months) in both periods, and particularly so in the later period (table 2). One third of deaths occurred at the weekend for infants $\leqslant 4$ months of age in 1993-98, 3.8\% more than for infants $\geqslant 5$ months. There was no significant weekend effect in the older group of infants in this period: deaths occurred more uniformly throughout the week, with 
Table 1 Percentage of weekend deaths, UK 1986-98

\begin{tabular}{llll}
\hline & $\%$ Weekend & $\%$ Sunday & $\%$ Saturday \\
\hline $1986-90$ & 31.30 & 16.39 & 14.91 \\
$(n=8147)$ & $(p<0.0001)$ & $(p<0.0001)$ & $(p=0.05)$ \\
$1993-98$ & 32.24 & 16.61 & 15.63 \\
$(n=2776)$ & $(p<0.0001)$ & $(p<0.001)$ & $(p=0.02)$ \\
\hline
\end{tabular}

Expected cases at the weekend $=28.57 \%$ and Saturday $=14.28 \%$.

slightly more deaths on Wednesday and Thursday compared to Saturday and Sunday. However, there was no significant difference in weekend percentages between the age groups in either period ( $p=0.80$ for $1986-90$ and $p=0.08$ for 199398). There was no evidence of a Saturday effect in the older infants in either period, and there were more deaths on Sundays in all groups.

As seasonality has been a recognised feature of SIDS for over 100 years," although less obvious since the "back to sleep" campaign, ${ }^{10}$ a further question was whether the weekend effect was more obvious in certain months of the year. The one sided hypothesis test was again used to determine whether there were significantly more deaths than expected at the weekend in each month of the year. The periods 1986-90 and 1993-98 were considered separately to see whether there are any changes between the two time periods. Only in June for 1986-90 and March for 1993-98 were there fewer weekend deaths than expected by chance (table 3 ).

It can also be seen that for 1986-90 the weekend effect seemed to occur mainly between July and January. As in 1993-98 this was mainly due to a Sunday effect but with a shift from the autumn months to the spring. Compared with the earlier period, the weekend effect was higher in January, February, April, May, June, and October, and lower in the other months. It should be noted that the much smaller sample size in the later period made any pattern more difficult to detect. Although the pattern is less convincing in 1993-98, it did appear to differ from the earlier period.

\section{DISCUSSION}

The increased incidence of SIDS at weekends has persisted or even marginally increased despite the overall reduction in incidence following the "back to sleep" campaign in the early 1990s. The current study of a large national data set has confirmed that the weekend effect in SIDS is real, that it has persisted, and that it is predominantly due to an increase in Sunday reported deaths. The reason for this can only be speculative and as suggested by others ${ }^{2-4}$ could be due to less parental attention to the needs of their infants on Saturday evenings and Sundays.

Table 2 Percentage of weekend deaths, $\leqslant 4$ months and $\geqslant 5$ months, UK 1986-98

\begin{tabular}{|c|c|c|c|c|}
\hline & \multicolumn{2}{|l|}{$1986-90$} & \multicolumn{2}{|l|}{ 1993-98 } \\
\hline & $\leqslant 4$ months & $\geqslant 5$ months & $\leqslant 4$ months & $\geqslant 5$ months \\
\hline & $\begin{array}{l}31.37 \\
(p<0.0001)\end{array}$ & $\begin{array}{l}31.05 \\
(p=0.01)\end{array}$ & $\begin{array}{l}33.06 \\
(p<0.0001)\end{array}$ & $\begin{array}{l}29.22 \\
(p=0.36)\end{array}$ \\
\hline \% Sunday & $\begin{array}{l}16.29 \\
(p<0.0001)\end{array}$ & $\begin{array}{l}16.72 \\
(p<0.01)\end{array}$ & $\begin{array}{l}16.99 \\
(p<0.001)\end{array}$ & $\begin{array}{l}15.20 \\
(p=0.26)\end{array}$ \\
\hline \% Saturday & $\begin{array}{l}15.08 \\
(p=0.04)\end{array}$ & $\begin{array}{l}14.33 \\
(p=0.48)\end{array}$ & $\begin{array}{l}15.20 \\
(p<0.01)\end{array}$ & $\begin{array}{l}14.02 \\
(p=0.43)\end{array}$ \\
\hline
\end{tabular}

Expected percentages for each day $=14.28 \%$ and $28.57 \%$ for weekends.

Probabilities refer to variation from expected (one sided $t$ test for proportions).

Table 3 Weekend effect by month of death, UK 1986-98

\begin{tabular}{llll}
\hline Month of death & \% Weekend & \% Sunday & \% Saturday \\
\hline 1986-90 & & & \\
January & $31.05(p=0.04)$ & $14.93(p=0.28)$ & $16.12(p=0.05)$ \\
February & $29.91(p=0.19)$ & $15.01(p=0.27)$ & $14.90(p=0.30)$ \\
March & $29.61(p=0.24)$ & $16.24(p=0.05)$ & $13.37(p=0.78)$ \\
April & $31.82(p=0.03)$ & $18.25(p<0.01)$ & $13.58(p=0.70)$ \\
May & $30.55(p=0.13)$ & $15.91(p=0.12)$ & $14.65(p=0.40)$ \\
June & $26.11(p=0.88)$ & $14.74(p=0.39)$ & $11.37(p=0.97)$ \\
July & $31.67(p<0.01)$ & $16.19(p=0.13)$ & $15.48(p=0.24)$ \\
August & $34.06(p<0.01)$ & $17.60(p=0.03)$ & $16.87(p=0.07)$ \\
September & $34.06(p<0.01)$ & $18.33(p<0.01)$ & $15.74(p=0.18)$ \\
October & $33.48(p<0.01)$ & $16.59(p=0.04)$ & $16.89(p=0.03)$ \\
November & $33.81(p<0.01)$ & $16.39(p=0.05)$ & $17.42(p<0.01)$ \\
December & $32.62(p<0.01)$ & $17.64(p<0.01)$ & $14.99(p=0.27)$ \\
& & & \\
1993-98 & & & $16.72(p=0.12)$ \\
January & $36.86(p<0.01)$ & $20.14(p<0.01)$ & $14.17(p=0.52)$ \\
February & $31.10(p=0.19)$ & $16.93(p=0.11)$ & $14.29(p=0.50)$ \\
March & $28.20(p=0.55)$ & $13.91(p=0.57)$ & $13.55(p=0.62)$ \\
April & $33.64(p=0.05)$ & $20.09(p=0.57)$ & $17.65(p=0.08)$ \\
May & $36.65(p<0.01)$ & $19.00(p=0.02)$ & $15.21(p=0.35)$ \\
June & $32.72(p=0.09)$ & $17.51(p=0.09)$ & $14.85(p=0.41)$ \\
July & $31.19(p=0.21)$ & $16.34(p=0.20)$ & $15.09(p=0.39)$ \\
August & $30.82(p=0.27)$ & $15.72(p=0.30)$ & $17.59(p=0.08)$ \\
September & $29.17(p=0.42)$ & $11.57(p=0.13)$ & $16.46(p=0.17)$ \\
October & $35.44(p=0.01)$ & $18.99(p=0.02)$ & $12.80(p=0.73)$ \\
November & $29.38(p=0.40)$ & $16.59(p=0.17)$ & $18.18(p=0.03)$ \\
December & $30.77(p=0.21)$ & $12.59(p=0.79)$ & \\
\hline & & &
\end{tabular}

Expected percentages for each day $=14.28 \%$ and $28.57 \%$ for weekends.

Probabilities refer to variation from expected (one sided $t$ test for proportions). 
The three data sources we used have some differences in inclusion criteria in that ONS (England \& Wales) excludes deaths defined as "unascertained" in contrast to their inclusion in the Scottish data and the Northern Ireland data. The Northern Ireland data also includes a small number of infants with bronchopneumonia (ICD 485) and interstitial pneumonia (ICD 516.8) as secondary diagnosis. The Northern Ireland data also extends the classification beyond the first year of life, although in the present study we limited our analysis to infants defined as $\leqslant 1$ year of age. These differences are unlikely to have substantively influenced the overall conclusions drawn from the data. Indeed, the subanalysis of datasets from the individual constituent parts of the United Kingdom failed to show any substantive difference when each of the datasets were analysed separately, namely that the weekend effect still remained and was consistent over both time periods (data available on request).

Reasons why the incidence of SIDS is higher at the weekend remain unclear.

However, this has been a consistent feature of many other similar reviews, ${ }^{1-4}$ although not all reported series. ${ }^{56}$ However, to our knowledge, this is the first report that has examined the weekend effect, both before and after the dramatic fall in prevalence associated with the "back to sleep" campaign.

The weekend effect was similar in infants both $\leqslant 4$ months and $\geqslant 5$ months for 1986-90, although it was slightly more noticeable in the younger infants. The observation that there was no significant weekend effect in infants $\geqslant 5$ months for 1993-98, suggested that the effect was in the post "back to sleep era", largely confined to younger infants. However, the difference between the weekend percentages for the two age groups was not significant and therefore it cannot be concluded that, for example, changes in the family routine at weekends have had a greater effect on the youngest group of infants.

The weekend effect noted here may represent a larger pattern of morbidity in the infant population at weekends.

\section{ACKNOWLEDGEMENTS}

The Scottish Cot Death Trust funded this work. Data were obtained from the Office for National Statistics, the Scottish Cot Death Trust, and the General Register Office in Northern Ireland.

\section{Authors' affiliations}

J A Mooney, I T Jolliffe, Department of Mathematical Sciences, University of Aberdeen, Aberdeen, UK

P J Helms, Department of Child Health, University of Aberdeen, Aberdeen, UK

\section{REFERENCES}

1 Brooke H, Gibson A, Tappin D, et al. Case-control study of sudden infant death syndrome in Scotland, 1992-95. BMJ 1997:314:1516.

2 Williams SM, Mitchell EA, Scragg R, et al. Why is sudden infant death syndrome more common at weekends? Arch Dis Child 1997;77:415-19.

3 Alm B, Norvenius SG, Wennergren G, et al. Changes in the epidemiology of sudden infant death syndrome in Sweden 1973-1996. Arch Dis Child 2001;84:24-30.

4 Dattani N, Cooper N. Trends in cot deaths. Health Statistics Quarterly 2000;5:10-16.

5 Leach CEA, Blair PS, Fleming PJ, et al. Epidemiology of SIDS and explained sudden infant deaths. Pediatrics 1999;104:e43.

6 Spiers PS, Guntheroth WG. The effect of weekend on the risk of sudden infant death syndrome. Pediatrics 1999; 104:e58.

7 Douglas AS, Helms PJ, Joliffe I. Seasonality of sudden infant death syndrome (SIDS) by age at death. Acta Paediatr 1998;87:1033-8.

8 Murphy MFG, Campbell MG. Sudden infant death syndrome and environmental temperature-an analysis using vital statistics. J Epidemiol Community Health 1987:41:63-71.

9 Wakley T. Infants found dead in bed. Lancet 1855;1:103.

10 Douglas AS, Helms PJ, Jolliffe IT. Seasonality of sudden infant death syndrome in mainland Britain and Ireland 1985-95. Arch Dis Child 1998:79:269-70.

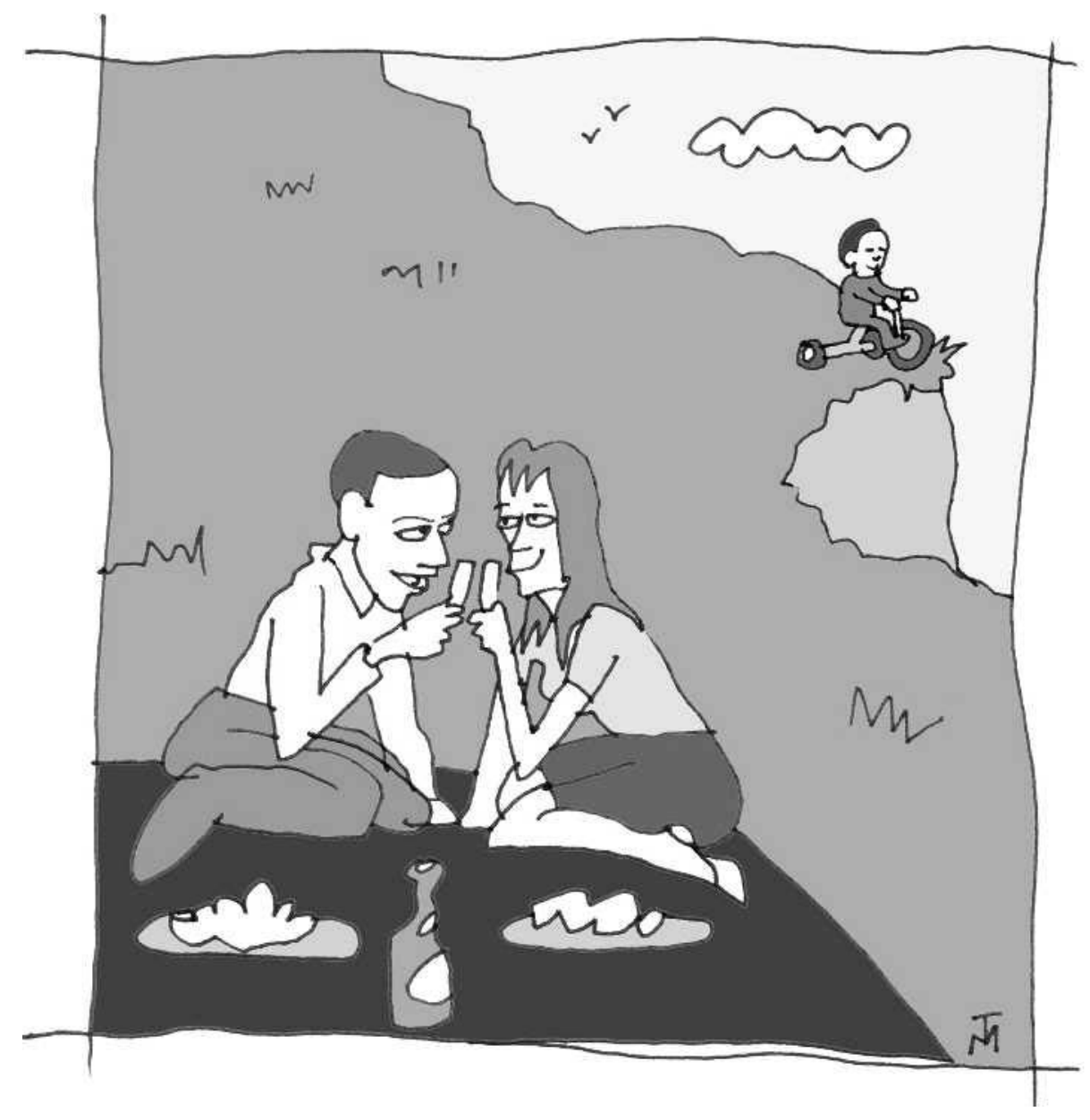

